\title{
AVALIAÇÃo DO DESCONFORTO TÉRMICO LOCAL EM CABINE DE AERONAVE COM INSUFLAMENTO DE AR PELO TETO E PELO PISO
}

\author{
Evandro Souza da Silva, Douglas Fabichak Junior e Arlindo Tribess \\ Escola Politécnica da Universidade de São Paulo
}

E-mails: evandrosouzadasilva@yahoo.com.br, douglasfabichak@gmail.com, atribess@usp.br

\section{RESUMO}

O sistema de ventilação é um dos mais importantes componentes do sistema de controle ambiental na correta distribuição do ar tratado para prover condições de saúde e de conforto em cabines. O sistema de ventilação por mistura (MV), utilizado atualmente em cabines de aeronaves, não tem propiciado condições adequadas de conforto térmico e pode, devido às suas características de mistura, propagar rapidamente doenças infecciosas na cabine. Sistemas de ventilação utilizados em ambientes de edificações, como o sistema de distribuição de ar por deslocamento (DV) e o sistema de distribuição de ar pelo piso (UFAD) e variantes destes sistemas, estão começando a ser propostos também para aeronaves. No presente trabalho foi realizado estudo comparativo do desconforto térmico local em cabine de aeronave com sistema de ventilação pelo teto (MV) e pelo piso (UFAD). Os ensaios foram realizados em mock-up de cabine de aeronave com 12 lugares. As pessoas foram simuladas utilizando manequins aquecidos. Foram levantados perfis de velocidade e de temperatura do ar e analisado ocorrência de estratificação de temperatura e risco de desconforto devido a correntes de ar. Os resultados mostraram a ocorrência de pequena estratificação de temperatura no sistema UFAD, mas sem grande impacto no risco de correntes de ar. Os resultados mostraram ainda que a utilização do sistema de insuflamento pelo piso, UFAD, em cabines de aeronaves é promissor. Uma possível alternativa para melhorar as condições de conforto com o sistema UFAD seria a realização de insuflamento misto do ar, parte pelo piso e parte pelo teto, com exaustão lateral do ar, que ainda precisa ser estudada.

Palavras-chave: desconforto térmico local, correntes de ar, insuflamento pelo piso, aeronaves

\section{INTRODUÇÃO}

A demanda por transporte aéreo de passageiros está aumentando como nunca foi visto anteriormente. Proporcionar um ambiente confortável, seguro e saudável no interior de uma cabine de aeronave comercial demandam tempo e investimento, principalmente devido às dificuldades para se reproduzir as condições de vôo, ou seja, altura típica de $11.000 \mathrm{~m}$, temperatura externa do ar em torno de $-55^{\circ} \mathrm{C}$, pressão atmosférica próxima de um quinto em relação à pressão ao nível do mar e umidade próxima a zero [1,2]. Somando-se às condições externas, a alta densidade de ocupação, geometria complexa e exposição a contaminantes torna-se desafiador projetar um ambiente interno de uma cabine de aeronave. 
O sistema de ventilação é um importante componente do sistema de controle ambiental desde que seja usado para distribuir ar limpo e condicionado adequadamente para a cabine. Atualmente, o sistema de ventilação por mistura (MV) é usado para distribuir ar no interior da cabine (Fig. 1). Ar tratado é insuflado na parte superior da cabine com alta velocidade e se desloca para baixo, sentido do piso, ao longo das laterais ou através da parte central da cabine, dependendo da orientação dos difusores de entrada de ar. Após alcançar o piso, parte do ar deixa a cabine através de saídas laterais e o restante sobe e encontra novamente o ar insuflado para formar a recirculação. Embora a temperatura na cabine seja uniforme, este sistema tem apresentado problemas de conforto térmico e pode, devido à característica de mistura, espalhar rapidamente doenças infecciosas [1-5]

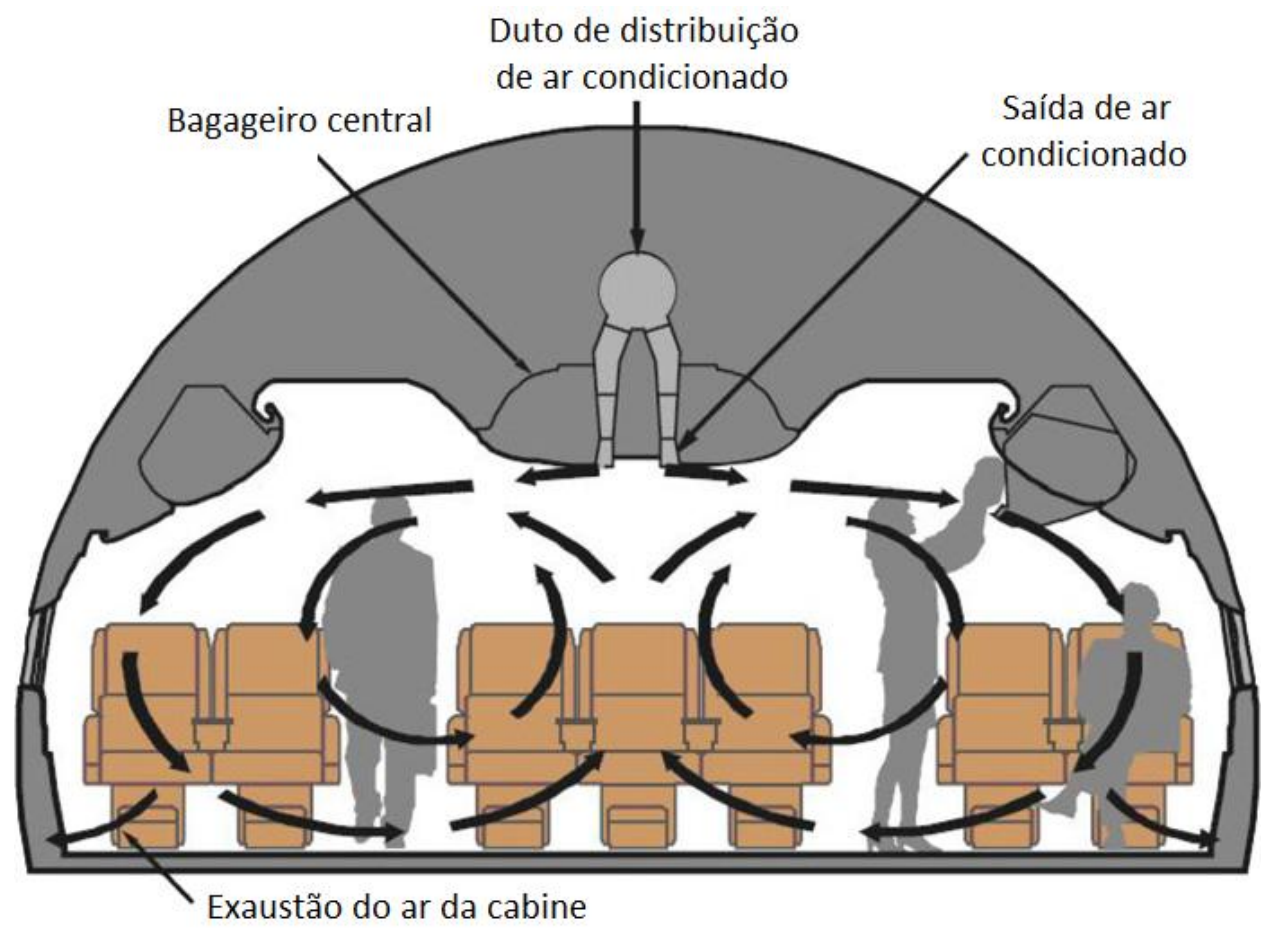

Figura 1 - Sistema de distribuição de ar por mistura, MV [1]

Para melhorar a distribuição de ar, novos conceitos de sistemas de ventilação como o insuflamento pelo piso (UFAD) e sistema personalizado (PV) estão sendo propostos [1-2,57]. O sistema de insuflamento pelo piso, Fig. 2, consiste em fornecer ar limpo e condicionado com baixa velocidade de insuflamento e pequena diferença de temperatura de um difusor montado no piso da cabine. $\mathrm{O}$ ar desloca-se para cima, assistido por plumas térmicas geradas pelos passageiros, e é exaurido através de difusores localizados na região do teto e laterais superiores junto aos bagageiros. Nesse sistema, recirculação local do ar pode existir. Adicional ao sistema de insuflamento pelo piso, o sistema personalizado que consiste no insuflamento de ar, com baixa velocidade, na região da zona de respiração está sendo pesquisado $[5,7]$.

Embora o sistema UFAD possa promover melhor qualidade do ar que um sistema de distribuição de ar por mistura, este pode causar estratificação de temperatura [7,8]. Esta estratificação de temperatura, juntamente com a velocidade e turbulência do ar, podem causar desconforto devido às correntes de ar (draught risk) [5,9]. 


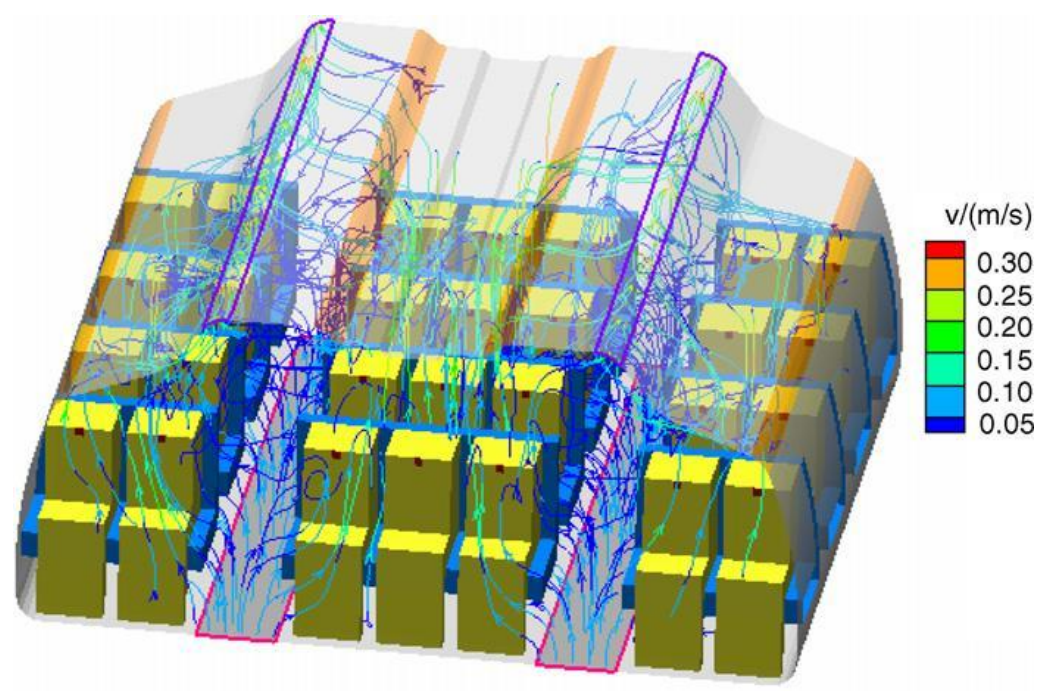

Figura 2 - Sistema de insuflamento pelo piso (UFAD), mostrando resultados de simulação numérica [1]

Segundo [10] "correntes de ar (draft ou draught) são um resfriamento local indesejado do corpo causado pelo movimento do ar". A sensibilidade a correntes de ar é maior em partes do corpo descobertas, especialmente na região da cabeça, pescoço e ombros e na região dos pés, tornozelos e pernas, e em atividade leve ou sedentária. Assim, a ocorrência de correntes de ar deve ser analisada principalmente na altura da cabeça e tronco das pessoas (1,10 $\mathrm{m}$ do piso para pessoas sentadas e $1,70 \mathrm{~m}$ para pessoas em pé). Se a pessoa estiver com as pernas descobertas, deve ser feita a verificação também na altura a 0,10 m do piso.

Correntes de ar foram identificados como um dos dois fatores ambientais mais irritantes em estações de trabalho e o fator mais irritante em escritórios [11,12,13]. Em ambientes de escritórios as correntes de ar podem fazer as pessoas desligarem sistemas de ventilação ou fecharem os difusores de ar. Os ocupantes também podem aumentar a temperatura do ar do ambiente para reagir às correntes de ar, principalmente no período do inverno [13]. Embora, as correntes de ar sejam a maior causa de reclamações, poucos estudos foram conduzidos a esse respeito.

Com relação a cabines de aeronaves, Gao e Niu utilizaram um código CFD (Computacional Fluid Dynamics) para simular e avaliar o sistema de distribuição de ar padrão, ou seja, ventilação por mistura (MV), de uma cabine de aeronave 767-300. Os autores também propuseram um sistema de distribuição de ar personalizado, flexível e ajustável, que fornece ar fresco $(2,5 \mathrm{~L} / \mathrm{s}$ por pessoa) diretamente para a zona de respiração e mais $7,5 \mathrm{~L} / \mathrm{s}$ por pessoa por meio de insuflamento padrão. Os autores concluíram que na maior parte da zona de ocupação (para o sistema MV), a velocidade do ar está entre 0,1 a 0,4 m/s, que é suficiente para evitar a sensação de ar estagnado e, também, a sensação de correntes de ar. Os autores nada mencionaram a respeito da sensação de correntes de ar para o sistema personalizado [14]. 
Zhang e Chen propuseram, também por meio de simulação numérica CFD, dois novos sistemas de ventilação e distribuição de ar no interior de uma cabine de aeronave. $O$ primeiro consistiu de insuflamento de ar pelo piso (UFAD) e retorno pela parte superior da cabine e o segundo de um sistema de distribuição personalizado em que metade da vazão de ar foi insuflada diretamente na zona de respiração por um dispositivo localizado na parte de traz da poltrona à frente do passageiro e a outra metade consistiu de insuflamento pelo piso. Foi verificado que, no sistema personalizado, a velocidade do ar permaneceu abaixo de $0,25 \mathrm{~m} / \mathrm{s}$ na região da cabeça e do peito e, portanto, era improvável que os passageiros sentissem desconforto causado pelas correntes de ar [1].

Observa-se da revisão bibliográfica, que nenhum estudo experimental trata da análise de conforto térmico em aeronaves com outro tipo de sistema de ventilação que não seja o sistema de mistura (MV), embora outros sistemas de ventilação em aeronaves estejam sendo estudados e testados [15].

A partir desse contexto, e devido aos problemas já relatados de conforto térmico e de qualidade do ar associados ao sistema de ventilação tradicional (MV), resolveu-se realizar estudos propondo e testando diferentes sistemas de ventilação e de distribuição de ar em mock-up de cabine de aeronave, como alternativa ao sistema de ventilação atualmente utilizado.

\section{OBJETIVO}

O objetivo do presente trabalho é avaliar condições de desconforto térmico local devido a correntes de ar e estratificação de temperatura em um mock-up de aeronave instrumentado dotado de sistema de ventilação pelo teto (MV) e pelo piso (UFAD).

\section{MÉTODO}

\subsection{Instalações}

A investigação experimental para avaliar os riscos de correntes de ar utilizando os sistemas por mistura e de insuflamento de ar pelo piso (UFAD) foi conduzida no Laboratório de Conforto Térmico e Qualidade do Ar da Escola Politécnica da Universidade de São Paulo em um mock-up instrumentado com três fileiras de quatro assentos por fileira, separadas por um corredor central, totalizando 12 assentos (Fig. 3).

\subsection{Sistemas de ventilação pelo piso e pelo teto}

As Figuras 4 e 5 apresentam representações esquemáticas dos sistemas de ventilação pelo piso (UFAD) e pelo teto (MV). Seguindo procedimento adotado em cabine de aeronaves, no insuflamento pelo teto, MV, $60 \%$ da vazão de ar foi insuflada pelos difusores junto à fuselagem e $40 \%$ pelos difusores localizados na parte superior dos bagageiros. De modo similar, no insuflamento pelo piso, UFAD, $60 \%$ da vazão de exaustão deu-se pelas grelhas laterais de retorno junto à fuselagem e $40 \%$ pelas grelhas de retorno acima dos bagageiros (Fig. 4 e 5). 

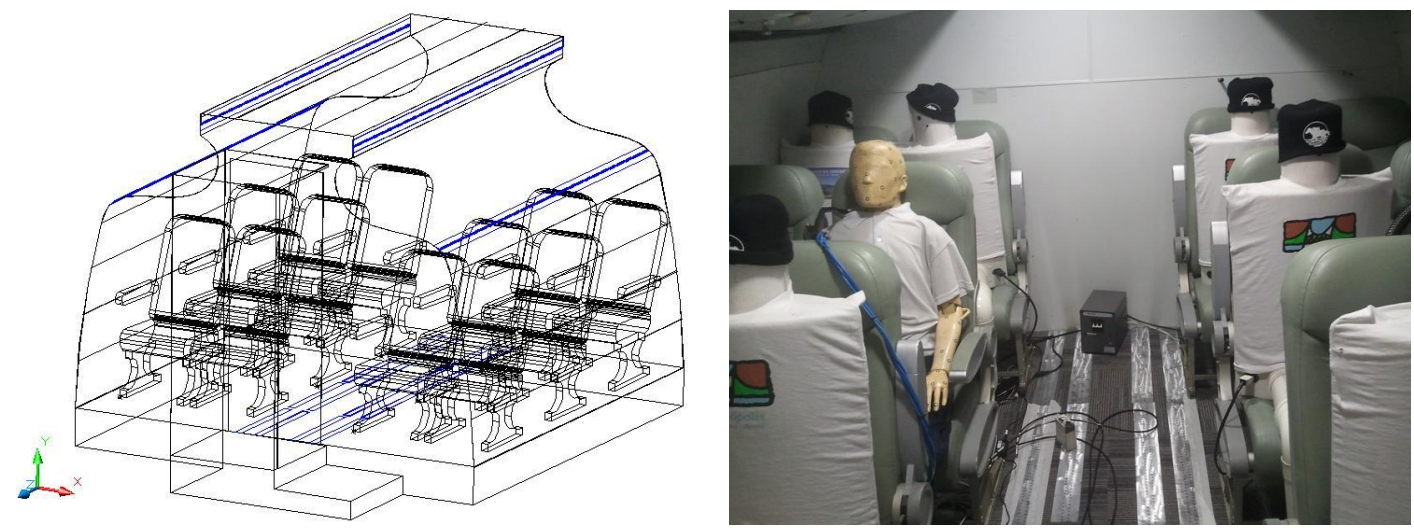

Figura 3 - Vista interna do mock-up e dos manequins aquecidos.

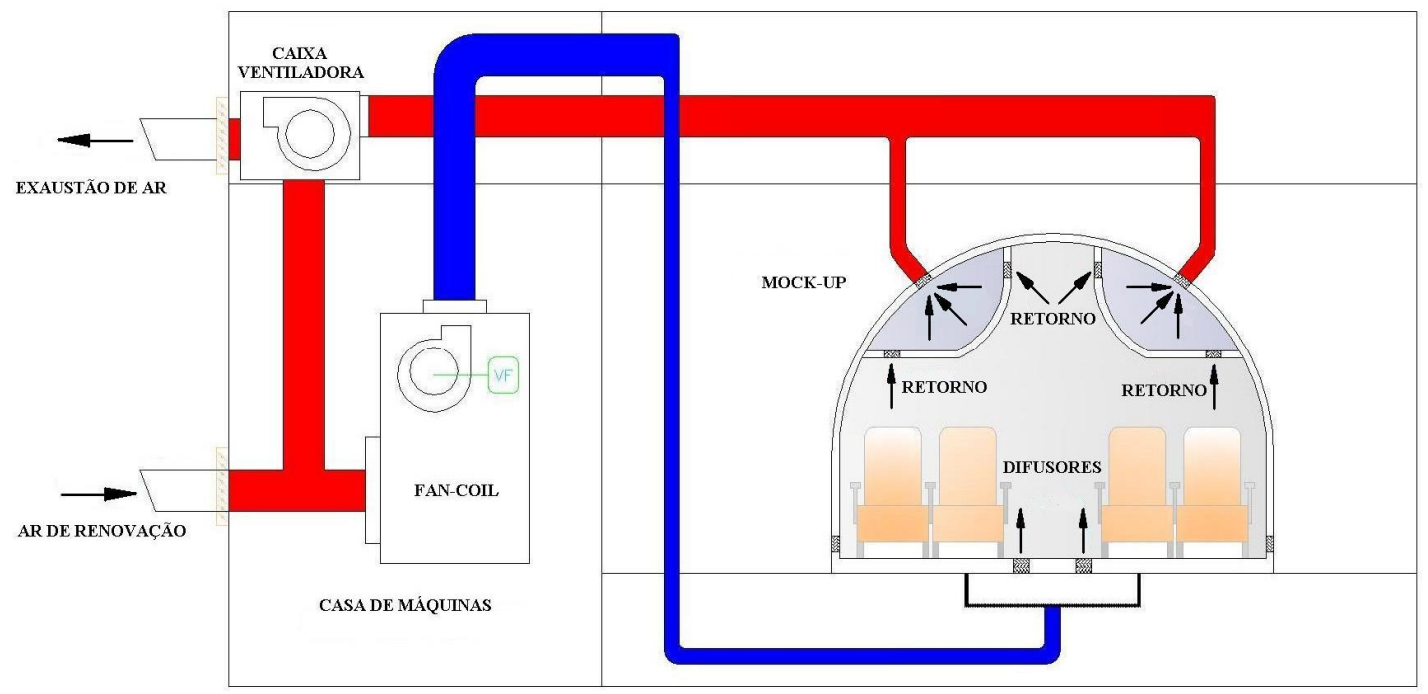

Figura 4 - Sistema de ventilação pelo piso (UFAD)

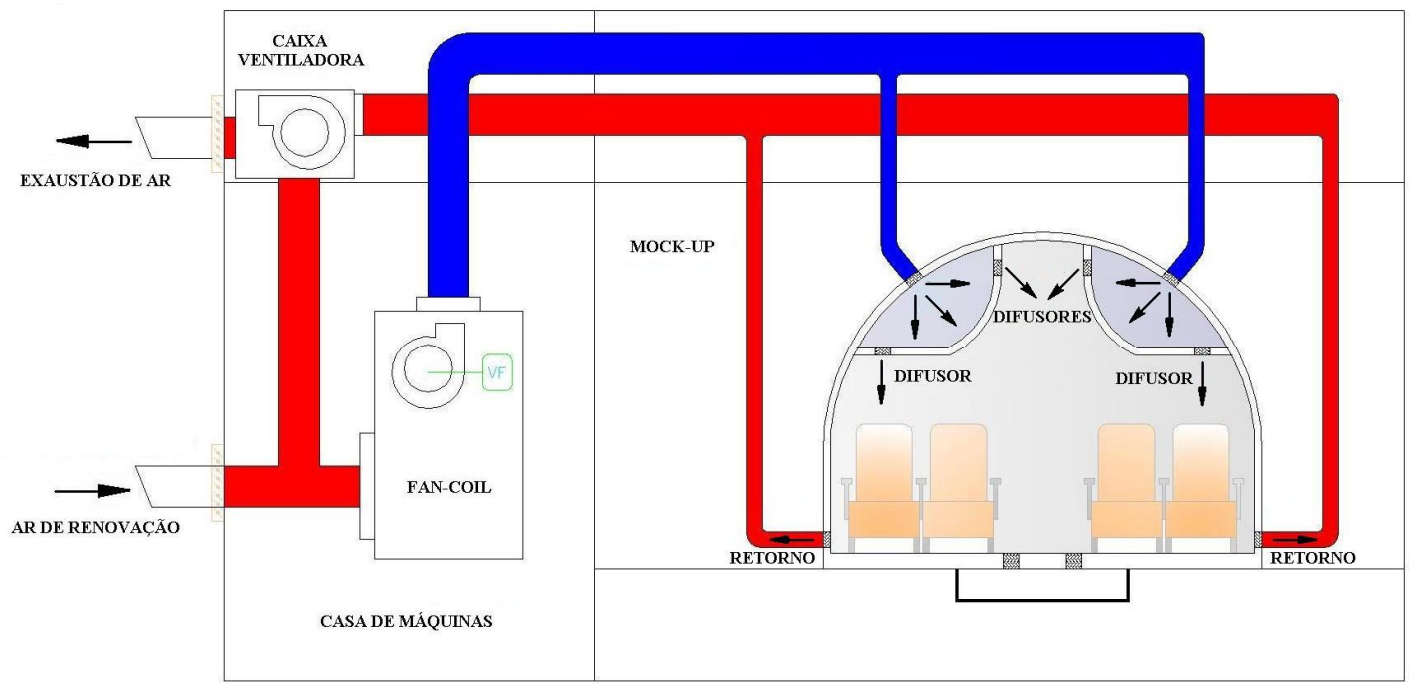

Figura 5 - Sistema de ventilação pelo teto (MV) 
A temperatura do ar de insuflamento foi ajustada para $18{ }^{\circ} \mathrm{C}$ e umidade relativa de $50 \%$. Em ambos os sistemas de ventilação, o ar foi insuflado a uma taxa de 9,4 L/s/pessoa, conforme estabelecido pela norma ASHRAE 161 (2007), totalizando uma vazão de $406,8 \mathrm{~m}^{3} / \mathrm{h}$, com $100 \%$ de renovação de ar. A vazão foi controlada e ajustada por meio de medição de velocidades nos dutos de retorno utilizando tubos de Pitot e manômetros diferenciais.

\subsection{Instrumentos e planos de medição}

A temperatura do ar, a velocidade do ar e o risco de correntes de ar (Draught Rate - DR) foram obtidos a partir de medições com o sistema ComfortSense da Dantec Dynamics, que consiste de três mini estruturas modulares, com entrada para um canal e dois drivers da National Instruments para fazer a conexão com o computador. Foram utilizados três transdutores, compostos de três sondas omnidirecionais para medição de velocidades do ar com freqüência de resposta de $5 \mathrm{~Hz}$ e com sensores de temperatura de resposta rápida integrados, com intervalo de operação de 0,05 até $10 \mathrm{~m} / \mathrm{s}$ e $-20{ }^{\circ} \mathrm{C}$ até $70{ }^{\circ} \mathrm{C}$, e incertezas de medição, respectivamente, de $\pm(0,02+0,02 \mathrm{~V}) \mathrm{m} / \mathrm{s}$ e $\pm 0,5{ }^{\circ} \mathrm{C}$, que atendem aos requisitos de precisão de equipamentos da norma ISO 7726 [17].

As temperaturas das paredes, piso, teto e manequim foram monitorados com um termômetro infravermelho, com faixa de operação entre $-30{ }^{\circ} \mathrm{C}$ a $90{ }^{\circ} \mathrm{C}$ e exatidão de \pm $0,75 \%$ da leitura ou $\pm 1{ }^{\circ} \mathrm{Co}$ que for maior. As medidas foram conduzidas em três planos longitudinais, três fileiras 1,2 e 3, e em cinco pontos transversais, colunas A, B, C, D e E, à três alturas distintas $0,10 \mathrm{~m}, 0,60 \mathrm{~m}$ e $1,10 \mathrm{~m}$ para os pontos simulando pessoas sentadas e, $0,10 \mathrm{~m}, 1,10 \mathrm{~m}$ e $1,70 \mathrm{~m}$ para os pontos do corredor central que simulou pessoas em pé (Fig. 6), totalizando 45 pontos de medição.
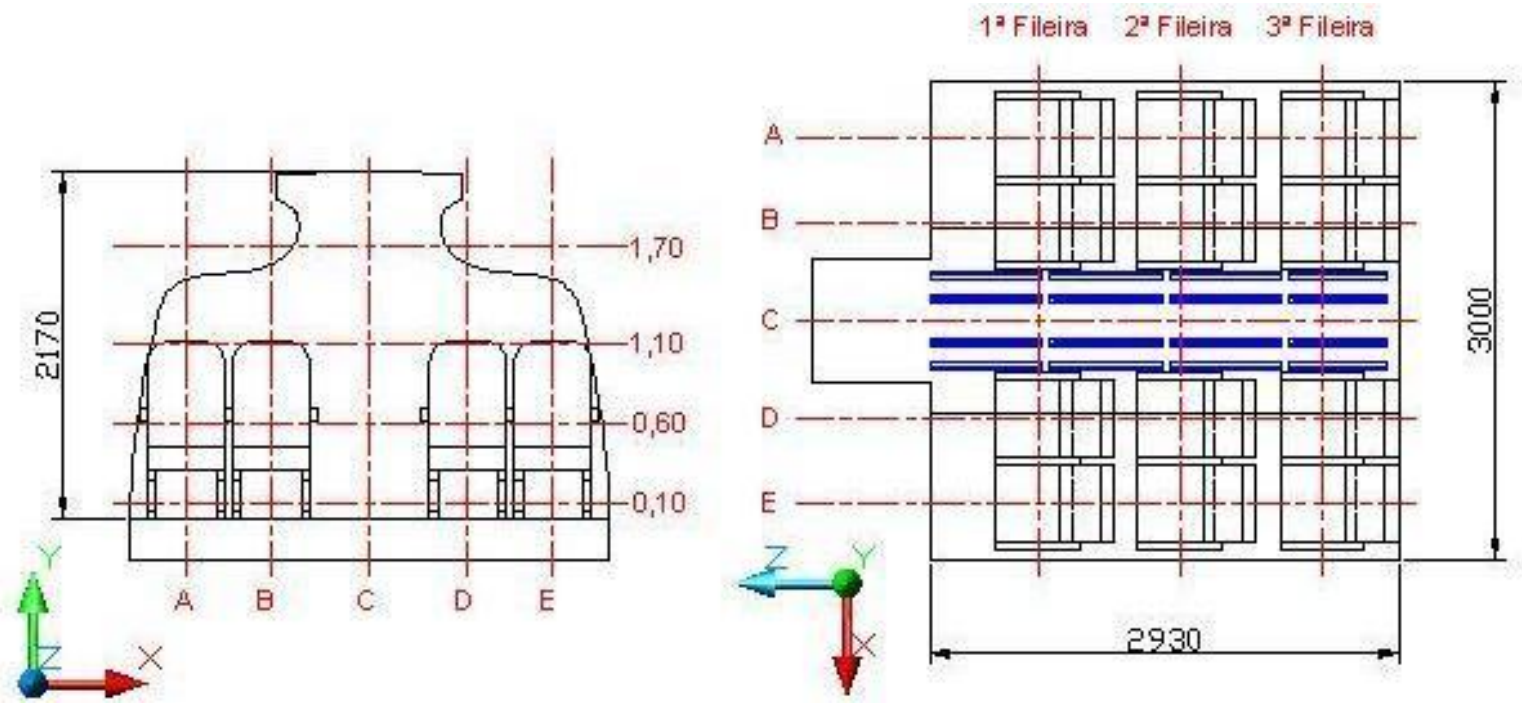

Figura 6 - Plano de medição de temperatura e velocidade do ar 


\subsection{Procedimento experimental}

A primeira parte do experimento foi conduzida com o sistema de insuflamento pelo piso (UFAD). Inicialmente, foi ligado o supervisório do sistema de condicionamento de ar e ajustada a temperatura de insuflamento em $18{ }^{\circ} \mathrm{C}$ e umidade relativa em $50 \%$. Em seguida, foi ajustada a velocidade do ventilador do fan coil e do plenum (insuflamento pelo piso) para $80 \%$ da capacidade máxima. Os dutos de exaustão foram ajustados para permitir a vazão total de $406,8 \mathrm{~m}^{3} / \mathrm{h}$, sendo $60 \%$ pelas grelhas laterais de retorno junto à fuselagem e $40 \%$ pelas grelhas de retorno acima dos bagageiros. Para minimizar os efeitos de perda de carga nos dutos de exaustão, foram instalados ventiladores centrífugos e, estes foram acionados antes de iniciar o ajuste da vazão. A vazão foi checada antes e após o experimento para certificar-se que não houve perda de ajuste após as medições.

Teste com fumaça foi conduzido para verificar a estanqueidade tanto do mock-up como dos dutos de exaustão e retorno. Os manequins foram ligados e o sistema ficou em operação antes de qualquer dado ser coletado. O sistema supervisório do CLP gerou gráfico tipo senóide de temperatura $\mathrm{x}$ tempo, o qual ilustrou exatamente o momento de estabilização do mock-up, que ocorreu por volta de 2 horas.

A segunda parte do ensaio foi conduzida com o sistema de mistura (MV). As grelhas lineares no piso foram substituídas por tampões e difusores foram instalados nos dutos superiores junto ao bagageiro. O insuflamento foi ajustado para a proporção de $60 \%$ da vazão de ar insuflada pelos difusores junto à fuselagem e $40 \%$ pelos difusores localizados na parte superior dos bagageiros. Os demais procedimentos foram similares ao sistema de insuflamento pelo piso.

No estudo foram utilizadas simultaneamente as três sondas omnidirecionais com sensores de temperatura para efetuar as medidas de velocidade e temperatura do ar e verificação do risco de correntes de ar. As três sondas com os sensores de temperatura foram instaladas nas alturas de $0,10 \mathrm{~m}, 0,60 \mathrm{~m}$ e 1,10 m em um suporte móvel, tipo tripé. Um total de 300 pontos foi registrado por cada sonda, na respectiva altura de medição. Portanto, cada posição da Figura 6 teve 900 registros em 5 minutos. Esse período foi estabelecido por meio da convergência da curva de temperatura, ou seja, período no qual a temperatura estabilizou. Quando o suporte era movido de uma posição para outra, antes de efetuar a próxima medição, esperava-se a estabilização do sistema, que ocorria por volta de 5 minutos para evitar erros na leitura das sondas devido ao movimento. Esse período de 5

minutos também foi estabelecido por meio da convergência da curva de temperatura, ou seja, do período de estabilização.

O termômetro infravermelho foi utilizado para medir as temperaturas das superfícies internas do mock-up bem como a temperatura superficial dos manequins aquecidos. Foram medidos seis pontos em cada superfície. Embora as temperaturas das superfícies não sejam perfeitamente uniformes, as condições térmicas de cada superfície são bem representadas pela temperatura média e desvio padrão. A Tabela 1 resume as temperaturas médias do presente estudo. 
Tabela 1 - Temperaturas internas do mock-up

\begin{tabular}{lcc}
\hline Temperatura & UFAD & MV \\
\hline Teto & $20 \pm 1$ & $21 \pm 1$ \\
Lateral esquerda & $20 \pm 1$ & $21 \pm 1$ \\
Lateral direita & $20 \pm 1$ & $22 \pm 1$ \\
Piso & $19 \pm 1$ & $23 \pm 1$ \\
Fundo & $19 \pm 1$ & $22 \pm 1$ \\
Frente & $21 \pm 1$ & $23 \pm 1$ \\
Manequim & $30 \pm 1$ & $30 \pm 1$ \\
Insuflamento & $18 \pm 1$ & $18 \pm 1$ \\
Média do ar (considerando as 45 & $21,0 \pm 0,1$ & $22,3 \pm 0,1$ \\
posições) &
\end{tabular}

3.5 Risco de desconforto devido a correntes de ar

Para a determinação do risco de correntes de ar (Draught Rate - DR), as normas ASHRAE 55 [18] e ISO 7730 [19] definem DR, para atividade leve ou sedentária, como [20]:

$\mathrm{DR}=\left(34-\mathrm{T}_{\mathrm{ar}}\right)\left(\mathrm{V}_{\mathrm{ar}}-0,05\right)^{0,62}\left(0,37 \mathrm{~V}_{\mathrm{ar}} \mathrm{T}_{\mathrm{u}}+3,14\right)$

Equação 1

Onde:

$\mathrm{T}_{\mathrm{ar}}=$ temperatura do ar

$\mathrm{V}_{\mathrm{ar}}=$ velocidade do ar $[\mathrm{m} / \mathrm{s}]$

$\mathrm{T}_{\mathrm{u}}=$ intensidade de turbulência

A intensidade de turbulência $T_{u}$ é a relação entre o desvio padrão da velocidade $\mathrm{DP}_{\mathrm{V}}$ pela velocidade média do ar $\mathrm{V}_{\mathrm{ar}}$, expressa em porcentagem. Essa relação pode ser calculada pela Equação 2 com base nos valores de velocidade de ar com intervalos de 0,2 segundos durante pelo menos 3 minutos e o desvio padrão da respectiva coleção de dados.

$$
T_{u}=\frac{D P_{V}}{V_{a r}} .100
$$

Equação 2

\section{ANÁLISE DOS RESULTADOS}

\subsection{Velocidades e temperaturas do ar}

As Fig. 7 e 8 mostram os perfis de velocidade e temperatura do ar para as quinze posições da Figura 6 para os dois sistemas, MV e UFAD. Em função da realização simultânea de ensaios de dispersão de partículas no ambiente, na poltrona 3E (Fig. 6) não foi colocado manequim térmico (região de injeção de partículas), razão pela qual os resultados na poltrona $3 \mathrm{E}$ são apresentados, mas não serão considerados na análise. 


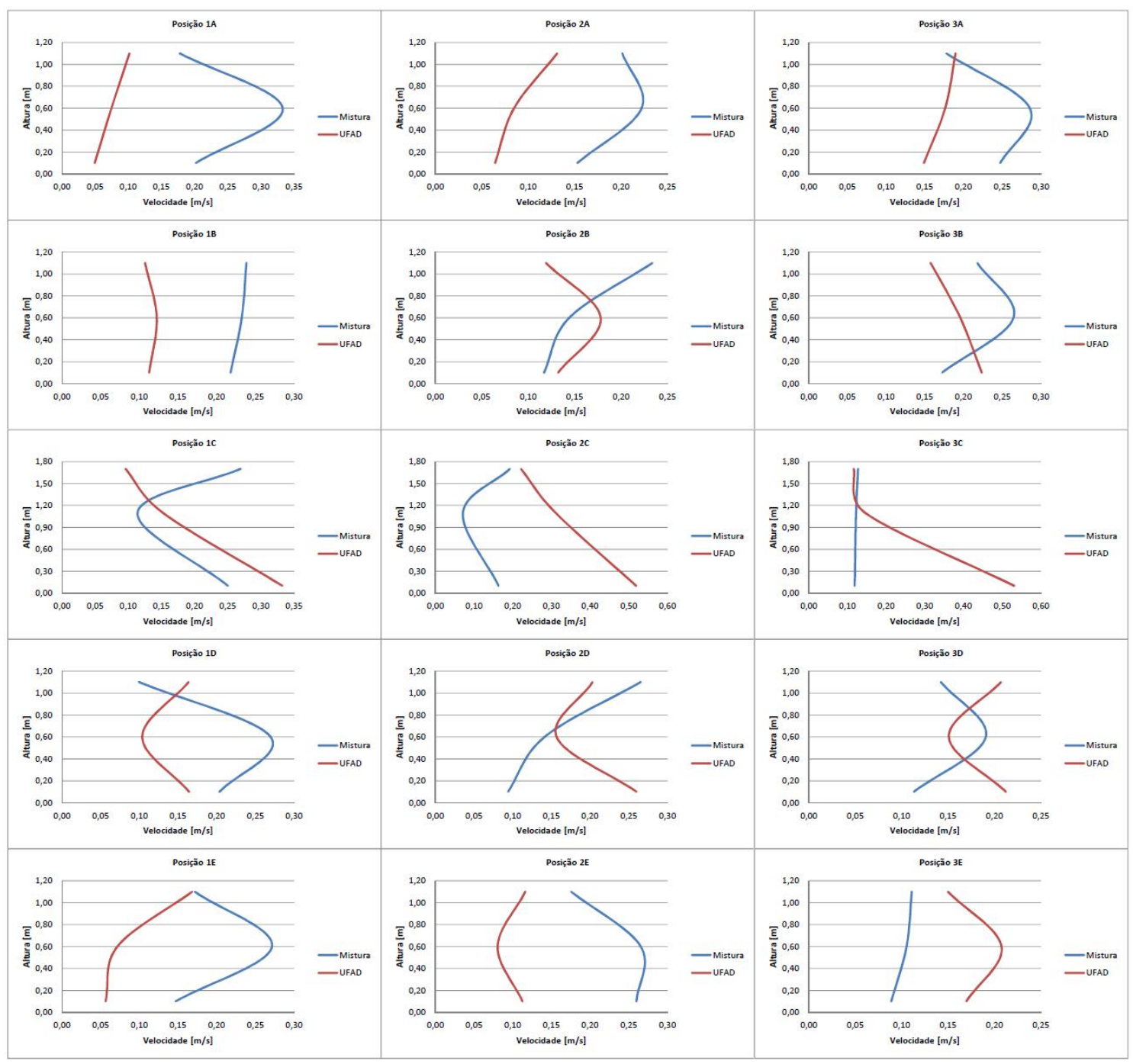

Figura 7 - Perfis de velocidade do ar para os sistemas de ventilação pelo piso, UFAD, e pelo teto, MV

Ao se comparar as velocidades do ar nas quinze posições do mock-up na Figura 7, pode-se observar que nas regiões próximas às paredes, o sistema pelo teto, MV, apresentou velocidades do ar superiores ao sistema de insuflamento pelo piso, UFAD. No sistema pelo teto, MV, ar é insuflado a alta velocidade através dos difusores instalados nos dutos próximos à fuselagem, com parte desse ar insuflado percorrendo as paredes laterais do mock-up, saindo pelas grelhas laterais, e parte do ar insuflado misturando-se no interior do mock-up. Essa mistura do ar na altura de 0,6 m ocasionou maiores velocidades do ar nesta altura. A pluma térmica gerada pelos manequins aquecidos também influenciou na velocidade do ar, na altura de 0,6 m. Ainda com relação ao sistema pelo teto, MV, foi observada simetria em relação à coluna C (corredor), onde as velocidades do ar apresentaram o mesmo perfil. Com relação ao sistema de insuflamento pelo piso, UFAD, este sistema apresentou, na maioria dos casos, perfis de velocidade ar com valores inferiores ao do sistema pelo teto, MV, exceto no corredor, em função do insuflamento do ar ocorrer nesta região no sistema UFAD. 


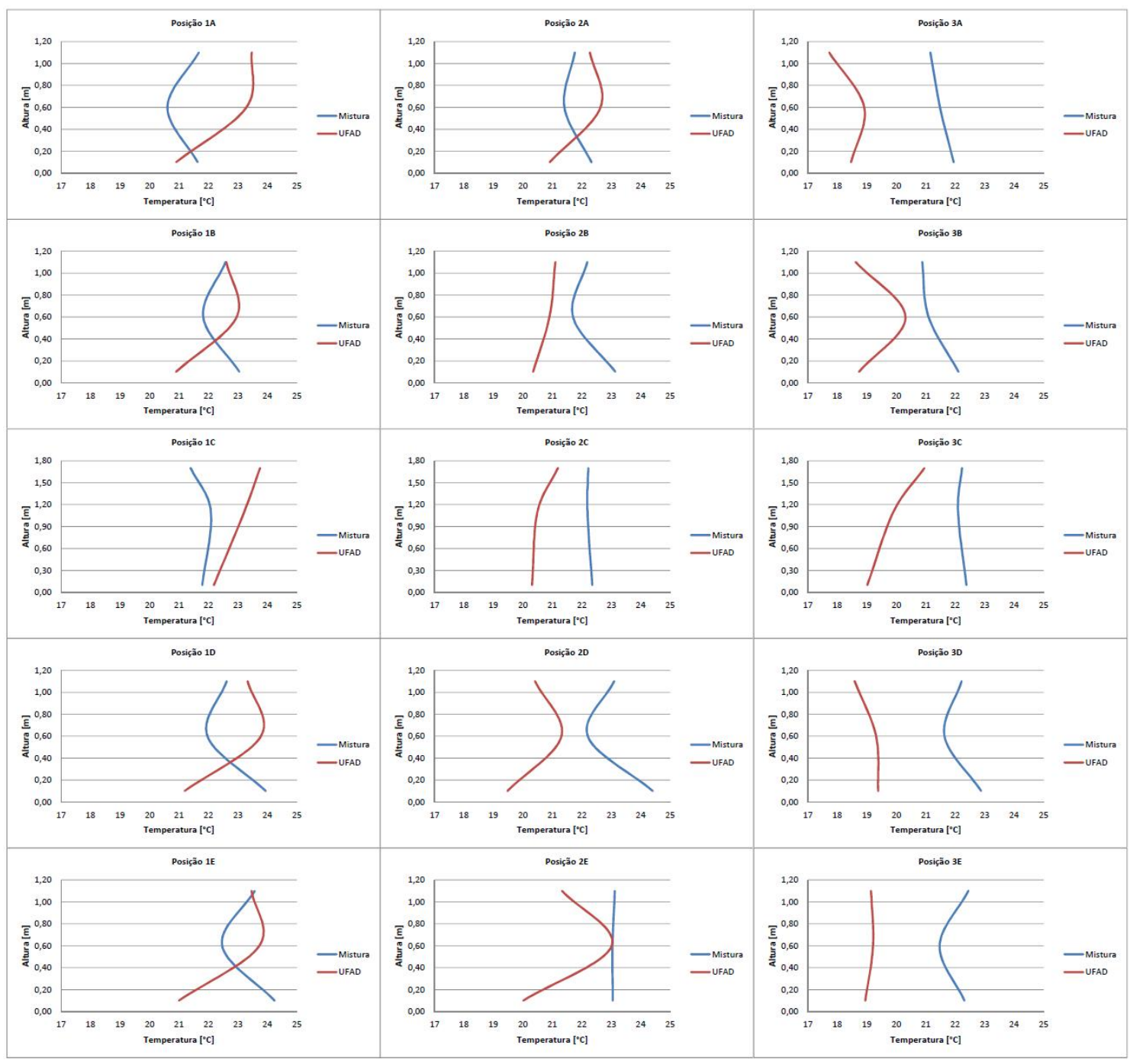

Figura 8 - Perfis de temperatura do ar para os sistemas de ventilação pelo piso, UFAD, e pelo teto, MV

Os resultados da Figura 8 mostram que o sistema pelo teto, MV, apresentou temperaturas mais uniformes e superiores em relação ao sistema de insuflamento pelo piso na maioria das posições analisadas. Essa uniformidade é devido às características de mistura que esse sistema apresenta. Além disso, os valores de temperatura do ar em relação às alturas mostraram-se praticamente constantes, não havendo estratificação de temperatura para esse sistema, o sistema MV. O sistema de insuflamento pelo piso, UFAD, por sua vez, apresentou temperaturas maiores na altura de $0,6 \mathrm{~m}$ em relação às demais alturas, relacionado com valores menores de velocidade do ar nessa altura em comparação ao sistema pelo teto, MV. Os valores de temperatura do sistema de insuflamento pelo piso, UFAD, mostram que existe uma diferença de temperatura do ar entre as alturas dos pés $(0,10 \mathrm{~m})$ e a altura da cabeça $(1,10$ $\mathrm{m}$ e $1,70 \mathrm{~m}$, pessoas sentadas e pessoas em pé, respectivamente). Essa diferença mostra que existe uma pequena estratificação da temperatura no interior do mock-up. As maiores diferenças de temperatura entre os pés e a cabeça foram de aproximadamente de $2{ }^{\circ} \mathrm{C}$ e, portanto, inferiores ao limite máximo preconizado pelas normas ASHRAE 55 [18] e ISO 7730 [19] de $3^{\circ} \mathrm{C}$. 
4.2 Risco de desconforto devido a correntes de ar

Finalmente, as Fig. 9 e 10 ilustram a porcentagem de pessoas insatisfeitas devido a correntes de ar, DR, no interior do mock-up para os sistemas de insuflamento por mistura, MV, e insuflamento pelo piso, UFAD, respectivamente.

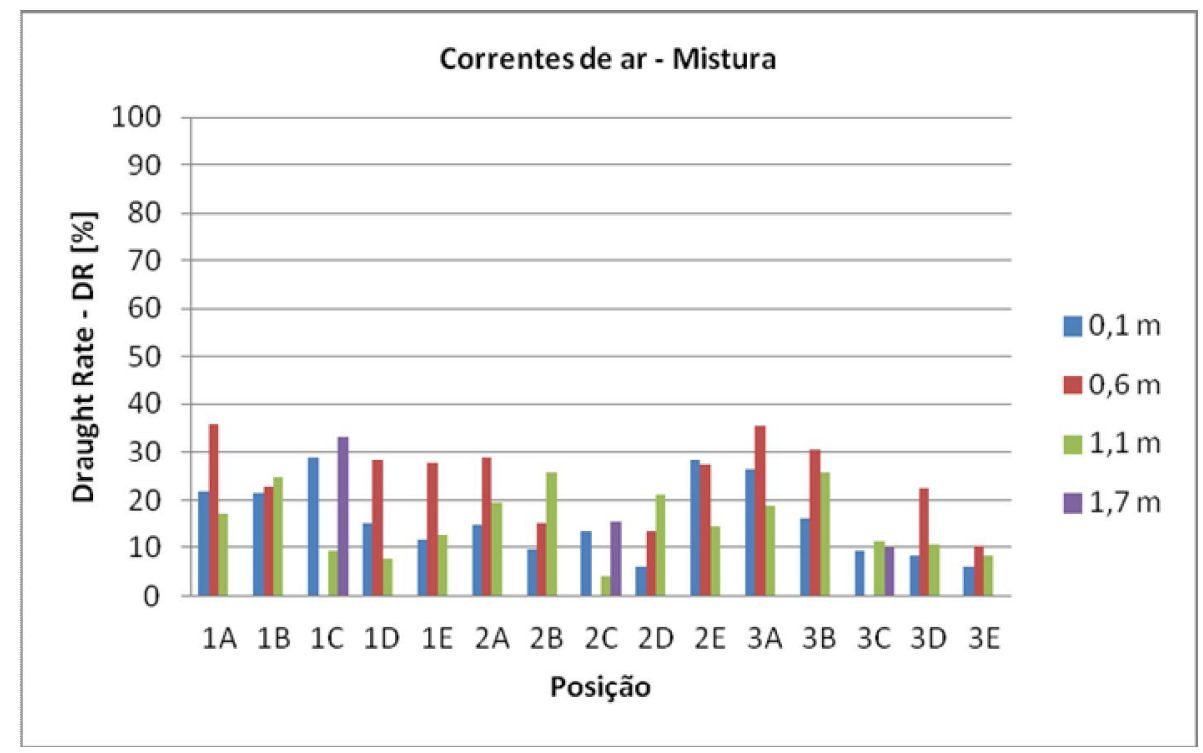

Figura 9 - Porcentagem de pessoas insatisfeitas devido a correntes de ar (DR) - Sistema de ventilação pelo teto, MV

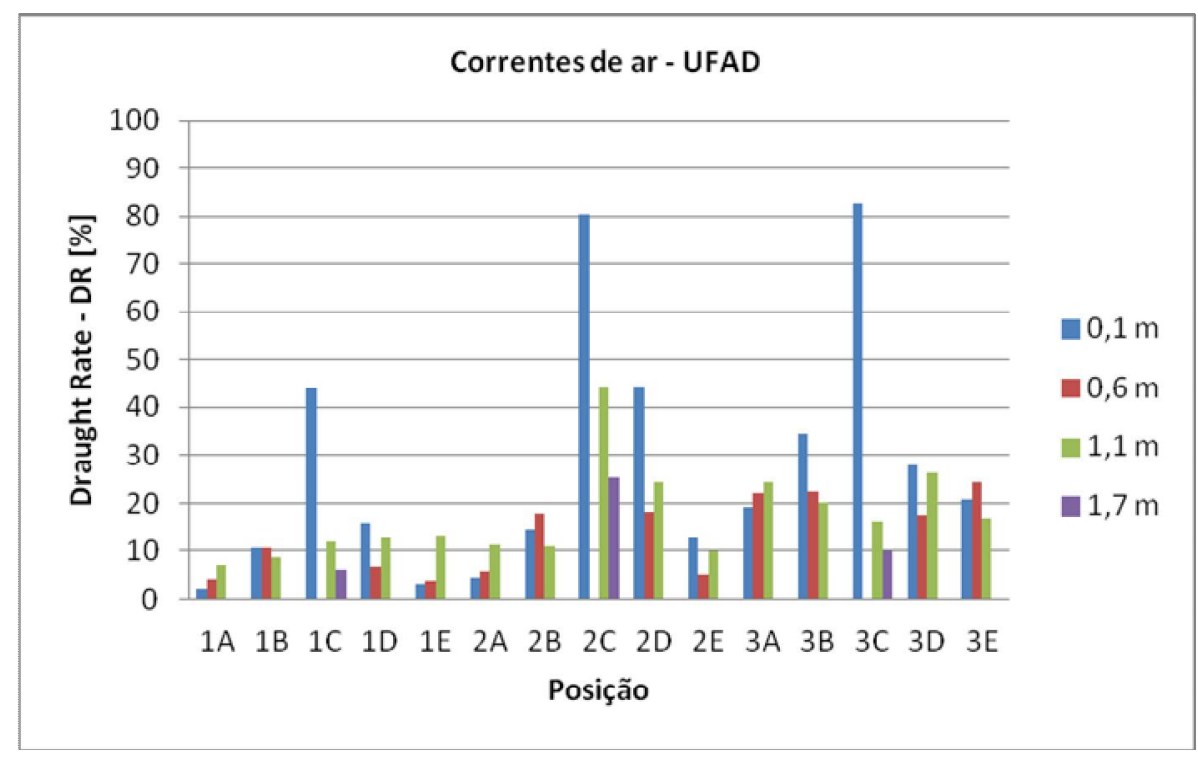

Figura 10 - Porcentagem de pessoas insatisfeitas devido a correntes de ar (DR) - Sistema de ventilação pelo piso, UFAD 
O percentual de pessoas insatisfeitas devido a correntes de ar, DR, no sistema de ventilação pelo teto, MV, é mais uniforme em relação às posições e alturas analisadas do que o sistema de insuflamento pelo piso, UFAD, embora se observe que na maioria das posições o percentual de pessoas insatisfeitas seja superior aos $20 \%$ no sistema MV. O sistema de insuflamento pelo piso, UFAD, por sua vez, possui uma região crítica de desconforto térmico ocasionado pelo risco de correntes de ar, a região central do mock-up, coluna $\mathrm{C}$ (corredor), na altura de $0,1 \mathrm{~m}$, em função da proximidade com o ar insuflado. Embora o risco de correntes de ar nessa região seja elevado, superior aos $40 \%$, as demais posições apresentam um resultado satisfatório, ou seja, inferior aos 20\%. Mesmo com a ocorrência de pequena estratificação da temperatura no sistema UFAD, esta estratificação não tem grande impacto no risco de correntes de ar. Verifica-se ainda no sistema UFAD que, quanto mais afastada for a posição da região do corredor, menor será o risco de correntes de ar.

\section{CONCLUSÃO}

Os resultados mostraram que o sistema de insuflamento pelo piso, UFAD, pode ser utilizado com sucesso em cabines de aeronaves, necessitando-se, naturalmente, a realização de um maior número de estudos e de análise de diferentes formas de realizar o insuflamento de ar na cabine pelo piso. Uma alternativa para melhorar as condições com o sistema UFAD seria a instalação de aletas defletoras nos difusores, de tal modo que o ar não seja insuflado diretamente no espaço das poltronas. Outra possibilidade seria a realização de insuflamento misto do ar, parte pelo piso e parte pelo teto, com exaustão lateral do ar, que ainda precisa ser estudada.

\section{REFERÊNCIAS}

[1] ZHANG, Tengfei; CHEN, Qingyan (Yan). Novel air distribution systems for commercial aircraft cabins. Building and Environment 42 1675-1684 (2007).

[2] WU, Chaofan; AHMED, Noor A. A novel mode of Ari supply for aircraft cabin ventilation. Building and Environment 56 47-56 (2012).

[3] ZHANG, Zhao; CHEN, Xi; MAZUMDAR, Sagnik; ZHANG, Tengfei; CHEN, Qingyan. Experimental and numerical investigation of airflow and contaminant transport in an airliner cabin mockup. Building and Environment 44 85-94 (2009).

[4] WANG, Aijun; ZHANG, Yuanhui; SUN, Yigang; WANG, Xinlei. Experimental study of ventilation effectiveness and air velocity distribuition in an aircraft cabin mockup. Building and Environment 43 337-343 (2008).

[5] ZHANG, (Tim) Tengfei; LI, Penghui; WANG, Shugang. A personal air distribution system with air terminals embedded in chair armrests on commercial airplanes. Building and Environment xxx 1-11 (2011).

[6] PEREIRA, M. L., GRAUDENZ, G., TRIBESS, A., MORAWSKA, L. Determination of particle concentration in the breathing zone for four different types of office ventilation systems. Building and Environment, 1-8, (2008).

[7] LEITE, B. C. C., TRIBESS, A. Analysis of Thermal Comfort in an Office Environment with Underfloor Air Supply in a Tropical Climate. HVAC\&R Research. 12(2):215-229, (2006).

[8] BAUMAN F., DAILY A. Underfloor air distribution (UFAD) design guide. ASHRAE. Atlanta, (2003). 
[9] ZUKOWSKI, M. A new formula for determining a minimum recommended value of inlet air velocity from UFAD system to prevent occupants from draught risk. Building and Environment, 42 171-179, (2007).

[10] ASHRAE 55. Thermal environmental conditions for human occupancy, American Society of Heating, Refrigerating and Air Conditioning Engineers Inc., Atlanta, (2004).

[11] BOLINDER, E., MAGNUSSON, E., NYREN, E., 1970, Risker i jobbet: LO-enkäten. LO-medlemmarnas uppfattning om arbetsplatsens hälsorisker (Stockholm: PRISMA) (in Swedish).

[12] ARBEJDSMILJøGRUPPEN, Arbejdmiljøundersøgelses rapport No. 2, Copenhagen (in Danish), (1972).

[13] FANGER, P. O., CHRISTENSEN, N. K. Perception of draught in ventilated spaces. Ergonomics, 1986, vol. 29, no. 2, 215-235, (1986).

[14] Gao N. P., Niu J. L., Personalized ventilation for commercial aircraft cabins. $45^{\text {th }}$ AIAA Aerospace Sciences Meeting and Exhibit. American Institute of Aeronautics and Austronautics, Inc., Nevada, (2007).

[15] DLR, DLR and Airbus flight-test new aircraft ventilation system. 2011. http://www.dlr.de/dlr/en/desktopdefault.aspx/tabid-10256/366_read-1664. Acessado em 05.04.2013.

[16] ASHRAE 161. Air Quality within Commercial Aircraft, American Society of Heating, Refrigerating and Air Conditioning Engineers Inc., Atlanta, (2007).

[17] ISO 7726. Thermal environments - Instruments and methods for measuring physical quantities, International Organization for Standardization, Geneva, (1998).

[18] ASHRAE 55. Thermal environmental conditions for human occupancy, American Society of Heating, Refrigerating and Air Conditioning Engineers Inc., Atlanta, (2004).

[19] ISO 7730. Ergonomics of the Thermal Environment - Analytical Determination and Interpretation of Thermal Comfort using Calculation of the PMV and PPD Indices and Local Thermal Comfort Criteria. International Organization for Standardization, Geneva, (2005).

[20] FANGER, P. O., MELIKOV, A. K., HANZAWA, H., RING, J. Air turbulence and sensation of draught. Energy and Buildings, 12 (1988) 21-39, (1988). 